\title{
Returning to work after multimodal treatment in glioblastoma patients
}

\author{
Daniele Starnoni, MD, ${ }^{1}$ Julien Berthiller, MD, ${ }^{2}$ Tania-Mihaela Idriceanu, MD, ${ }^{1}$ \\ David Meyronet, MD, PhD, ${ }^{4-6}$ Anne d'Hombres, MD, François Ducray, MD, PhD, ${ }^{3-5}$ and \\ Jacques Guyotat, MD, PhD'
}

\begin{abstract}
${ }^{1}$ Neurosurgical Department, Oncological and Vascular Service, Pierre Wertheimer University Hospital, Lyon; ${ }^{2}$ Clinical Investigation Centre CIC-INSERM 1407, EPICIME, Department of Clinical Pharmacology, Hospices Civils de Lyon; ${ }^{3}$ Hospices Civils de Lyon, Groupe Hospitalier Est, Service de Neuro-Oncologie, Lyon; “Université Claude Bernard Lyon 1, Lyon; ${ }^{5}$ Department of Cancer Cell Plasticity, Cancer Research Centre of Lyon, INSERM U1052, CNRS UMR5286, Lyon; ${ }^{6}$ Hospices Civils de Lyon, Groupe Hospitalier Est, Service de Neuropathologie, Lyon; and 'Département de Radiothérapie, Centre Hospitalier Universitaire Lyon Sud, Pierre-Bénite, France
\end{abstract}

OBJECTIVE Although multimodal treatment for glioblastoma (GBM) has resulted in longer survival, uncertainties exist regarding health-related quality of life and functional performance. Employment represents a useful functional end point and an indicator of social reintegration. The authors evaluated the rate of patients resuming their employment and the factors related to work capacity.

METHODS The authors performed a retrospective study of working-age patients treated with surgery and radiochemotherapy between 2012 and 2015. Data were collected before and after surgery and at 6, 12, 18, and 24 months. Employment was categorized according to the French Socio-Professional Groups and analyzed regarding demographic and clinical data, performance status, socio-professional category, radiological features, type, and quality of resection.

RESULTS A total of 125 patients, mean age 48.2 years, were identified. The mean follow-up was 20.7 months with a median survival of 22.9 months. Overall, 21 patients (18.3\%) went back to work, most on a part-time basis $(61.9 \%)$. Of the patients who were alive at $6,12,18$, and 24 months after diagnosis, $8.7 \%, 13.8 \%, 15.3 \%$, and $28.2 \%$, respectively, were working. Patients going back to work were younger $(p=0.03)$, had fewer comorbidities $(p=0.02)$, and had a different distribution of socio-professional groups, with more patients belonging to higher occupation categories $(p=$ 0.02). Treatment-related symptoms $(36.2 \%)$ represented one of the main factors that prevented the resumption of work. Employment was strongly associated with performance status $(p=0.002)$ as well as gross-total removal $(p=0.04)$. No statistically significant difference was found regarding radiological or molecular features and the occurrence of complications after surgery.

CONCLUSIONS GBM diagnosis and treatment has a significant socio-professional impact with only a minority of patients resuming work, mostly on a part-time basis.

https://thejns.org/doi/abs/10.3171/2018.3.FOCUS1819

KEYWORDS glioblastoma; return to work; multimodal treatment; employment

$\mathrm{G}$ LIOBLASTOMA (GBM) represents the most common malignant primary brain tumor in adults, with an estimated annual incidence of 3000 cases in France. ${ }^{25}$ The standard treatment consists of surgery, followed by concomitant radiochemotherapy and adjuvant temozolomide (Stupp protocol). ${ }^{24}$ Chemoradiation treatment has resulted in a better outcome with a 2-year overall survival (OS) of up to $27 \%$ and a 5-year survival of up to $10 \% .10,24$
Although the multimodal treatment for GBM has resulted in longer survival, uncertainties exist regarding health-related quality of life (HRQOL), and few clinical studies have addressed the functional end points in highgrade gliomas. ${ }^{2,17,23}$

The ability to return to work may represent a useful functional parameter and an indicator of social reintegration with a significant impact on a patient's self-worth. ${ }^{3,14}$ The socio-economic independence is undoubtedly related

ABBREVIATIONS GBM = glioblastoma; HRQOL = health-related quality of life; $\mathrm{KPS}=$ Karnofsky Performance Status; OS = overall survival.

SUBMITTED January 13, 2018. ACCEPTED March 15, 2018.

INCLUDE WHEN CITING DOI: 10.3171/2018.3.FOCUS1819. 
to the working capacity and not only allows individuals to maintain their social status but also affects the sense of future certainty, ${ }^{19}$ which has been shown to represent an additional prognostic value for death risk stratification in unresectable GBM. ${ }^{19}$

Numerous factors come into play in the socio-economic analysis of GBM patients, and the parameters to consider are multifactorial. Cognitive and functional deficits and the direct effects of chemoradiotherapy could impact differently the ability to return to work, depending on the socio-professional category of the patient, as well as the socio-cultural context and specific health care system of each country. We aimed to evaluate the rate of patients resuming their employment and assess the factors related to work capacity in GBM patients.

\section{Methods}

We performed a single-center, retrospective cohort study of all working-age GBM patients who were referred to and underwent follow-up at the neurosurgical department of Pierre Wertheimer Neurological Hospital in Lyon, France, between January 2012 and December 2015.

To avoid bias due to early retirement, we included all patients younger than 59 years at diagnosis. All patients, who were referred to different oncological centers immediately after surgical treatment or diagnosis were excluded. Exclusion criteria also included unemployed patients and full-time students.

Follow-up information was obtained from periodic visits to our neuro-oncological clinic, and data were derived from our oncological and neurosurgical database and case notes. The date of diagnosis was recorded as the time of initial surgery, and all patients had histological confirmation of GBM, whether on biopsy or resection. Clinical and radiological information was registered and obtained at diagnosis; after surgery; and at 6,12, 18, and 24 months.

The database included comorbidities, presenting clinical signs and symptoms, radiological features, the type of surgery (biopsy vs resection) and extent of surgical removal (gross-total vs subtotal/partial removal), and surgeryrelated complications.

When available, the extent of resection was analyzed on postoperative T1-weighted gadolinium-enhanced MRI and deemed partial if the residual lesion was $>10 \mathrm{~cm}^{3}$ and subtotal if $<10 \mathrm{~cm}^{3}$. In the absence of a postoperative MRI study, the extent of resection was inferred from the operative protocol. Information regarding performance status, current treatment, and employment was recorded at every time point. Performance status at baseline and follow-up was assessed according to the Karnofsky Performance Status scale (KPS).

Employment was defined as an employed or self-employed job and categorized according to the French socioprofessional groups. The ability to return to work was recorded at every time point (no return to work vs part-time activity, less than $80 \%$ of contractual working hours vs full-time activity). The exact date (month and day) related to the resumption of work, as well as its precise duration, was not precisely reported and could only be estimated with an error of about 30-45 days corresponding to the maximum time gap between one consultation and another. When recorded, reasons for not returning to work were reported.

Employment was analyzed in relation to demographic and clinical data, specific time-point performance status, socio-professional category, radiological features, and type and quality of resection.

\section{Statistical Analysis}

Categorical variables are expressed as number and percentage. Quantitative variables are expressed as the mean \pm standard deviation when the distribution was normal or median and minimum and maximum when the distribution was not normal. The hypothesis of the normal distribution of quantitative variables was tested using the Kolmogorov-Smirnov test and graphically confirmed with a histogram. Categorical variables were compared using the chi-square test or Fisher's exact test when the conditions of application of chi-square test were not met. Quantitative variables were compared between groups using the nonparametric Wilcoxon signed-rank test. The statistical test is bilateral, and the level of significance was set to 5\% $(\mathrm{p}<0.05)$. Statistical analyses were conducted using SAS (version 9.4, SAS Institute Inc.). Due to the limited sample size no multivariate analysis was carried out.

\section{Results}

\section{Patient Characteristics}

One hundred twenty-five patients (48 female [38.4\%] and 77 male [61.6\%], mean age at diagnosis 48.2 years [range 23-58 years]), were included in this retrospective study. Patient characteristics are summarized in Table 1.

The frontal lobe appeared to be the most frequent location $(31.2 \%)$, followed by the occipital $(28 \%)$, parietal $(18.4 \%)$, and temporal $(2.4 \%)$ lobes. In $16.8 \%$ of cases the lesion was either localized in the deep brain or involved it; 4 patients presented with a primary brainstem lesion. A midline infiltration across the corpus callosum or involving the brainstem was present in $18.4 \%$ of patients, with $6.4 \%$ presenting with hydrocephalus as the first clinical manifestation. Resection was performed in 67 patients (53.6\%), and a gross-total removal was attained in $39(58.2 \%)$ of cases. A biopsy was performed in 58 patients (46.4\%).

Twenty-one $(16.8 \%)$ patients experienced at least one surgery-related complication, which included new or worsening focal neurological deficit (10.4\%), intraparenchymal hemorrhage (4.8\%), surgical site infections (3.2\%) needing removal of bone flap and long-term antibiotic therapy, hydrocephalus (1.6\%) requiring a ventriculoperitoneal shunt, and pulmonary embolism (1.6\%) without hemodynamic instability.

Sixteen patients (12.8\%) underwent a second surgery for local recurrence with a mean delay of 20.2 weeks (range 8-64 weeks) from the first surgery. Molecular characterization was performed and available in 123 patients (98.4\%); 7 patients (5.7\%) were found with IDH mutations, and methylation of the MGMT promoter was detected in $48(40.7 \%)$ patients. The median follow-up was 20.7 months (range 0.6-60.1 months), and the median overall survival was 22.9 months. 
TABLE 1. Population characteristics

\begin{tabular}{|c|c|c|}
\hline & Value* $^{*}$ & $\%$ \\
\hline Mean age in yrs (range) & $48.2(23-58)$ & \\
\hline \multicolumn{3}{|l|}{ Sex } \\
\hline Female & 48 & 38.4 \\
\hline Male & 77 & 61.6 \\
\hline \multicolumn{3}{|l|}{ Type of work } \\
\hline Employed & 112 & 89.6 \\
\hline Self-employed & 13 & 10.4 \\
\hline \multicolumn{3}{|l|}{ Socio-professional group } \\
\hline Agricultural workers & 0 & 0 \\
\hline Craftsmen, merchants, managing directors & 10 & 8.0 \\
\hline $\begin{array}{l}\text { Executive employees \& intellectual profes- } \\
\text { sions }\end{array}$ & 24 & 19.2 \\
\hline Intermediary professions & 42 & 33.6 \\
\hline Employees & 24 & 19.2 \\
\hline Workers & 25 & 20.0 \\
\hline \multicolumn{3}{|l|}{ Major comorbidities } \\
\hline No & 104 & 83.2 \\
\hline Yes $(\geq 1)$ & 21 & 16.8 \\
\hline \multicolumn{3}{|l|}{ Presenting signs \& symptoms } \\
\hline Headache & & 58.4 \\
\hline Seizure & & 44.8 \\
\hline Focal neurological deficits & & 33.6 \\
\hline Cognitive deterioration & & 32 \\
\hline Speech disturbances & & 25.6 \\
\hline Intracranial hypertension & & 24 \\
\hline Gait disturbances & & 13.6 \\
\hline Acute confusion & & 13.6 \\
\hline Drowsiness & & 12 \\
\hline \multicolumn{3}{|l|}{ Laterality } \\
\hline Rt & 53 & 42.4 \\
\hline Lt & 59 & 47.2 \\
\hline Bilateral & 9 & 7.2 \\
\hline Median & 4 & 3.2 \\
\hline \multicolumn{3}{|l|}{ Location } \\
\hline Frontal & 39 & 31.2 \\
\hline Parietal & 23 & 18.4 \\
\hline Occipital & 35 & 28 \\
\hline Temporal & 3 & 2.4 \\
\hline Deep brain & 21 & 16.8 \\
\hline Other (brainstem) & 4 & 3.2 \\
\hline \multicolumn{3}{|l|}{ Midline invasion } \\
\hline No & 102 & 81.6 \\
\hline Yes & 23 & 18.4 \\
\hline \multicolumn{3}{|l|}{ Type \& extent of surgery } \\
\hline Biopsy & 58 & 46.4 \\
\hline Open biopsy & 11 & 19 \\
\hline Neuronavigation-guided biopsy & 47 & 81 \\
\hline Resection & 67 & 53.6 \\
\hline Total removal & 39 & 58.2 \\
\hline Subtotal removal residual $\left(<10 \mathrm{~cm}^{3}\right)$ & 18 & 26.9 \\
\hline Subtotal removal residual $\left(>10 \mathrm{~cm}^{3}\right)$ & 10 & 14.9 \\
\hline
\end{tabular}

CONTINUED IN NEXT COLUMN »

\section{» CONTINUED FROM PREVIOUS COLUMN}

TABLE 1. Population characteristics

\begin{tabular}{|c|c|c|}
\hline & Value* & $\%$ \\
\hline \multicolumn{3}{|l|}{ Postop complications } \\
\hline No & 104 & 83.2 \\
\hline Yes & 21 & 16.8 \\
\hline New or worsening focal neurological deficit & 13 & 10.4 \\
\hline Intraparenchymal hemorrhage & 6 & 4.8 \\
\hline Surgical site infections & 4 & 3.2 \\
\hline Hydrocephalus & 2 & 1.6 \\
\hline Pulmonary embolism & 2 & 1.6 \\
\hline \multicolumn{3}{|l|}{ Mean KPS score (range) } \\
\hline Preop & \multicolumn{2}{|l|}{$78.3(30-100)$} \\
\hline Discharge & \multicolumn{2}{|l|}{$79.4(30-100)$} \\
\hline \multicolumn{3}{|l|}{ Oncological treatment } \\
\hline Radiotherapy + chemotherapy & 118 & 94.4 \\
\hline Chemotherapy & 6 & 4.8 \\
\hline Radiotherapy & 1 & 0.8 \\
\hline \multicolumn{3}{|l|}{ Molecular characterization } \\
\hline IDH-1 mutations $†$ & 7 & 5.7 \\
\hline MGMT methylationf & 48 & 40.7 \\
\hline Mean follow-up in mos (range) & \multicolumn{2}{|l|}{$20.7(0.6-60)$} \\
\hline Median of OS in mos & \multicolumn{2}{|l|}{22.9} \\
\hline OS at $1 \mathrm{yr}$ & \multicolumn{2}{|l|}{$78.6 \%$} \\
\hline OS at $2 \mathrm{yrs}$ & \multicolumn{2}{|l|}{$47 \%$} \\
\hline
\end{tabular}

* Values are presented as the number of patients unless stated otherwise.

† Data available for 123 patients.

$\ddagger$ Data available for 118 patients.

\section{Employment Status}

Definite data regarding the resumption of work activity and professional category was available for all patients (Tables 1 and 2). The majority of patients, $89.6 \%$, had an employed job and only $10.4 \%$ were self-employed; all worked full time. According to the French socio-professional groups, the patients in our cohort had an intermediary profession in $33.6 \%$ of cases, followed by workers (20\%); executive employees and intellectual professions (19.2\%); employees (19.2\%); and artisans, craftsmen, merchants, and managing directors $(8 \%)$.

Of the patients who were alive at $6,12,18$, and 24 months after diagnosis, $8.7 \%, 13.8 \%, 15.3 \%$, and $28.2 \%$, respectively, were working. Overall, of the 115 patients alive 6 months after diagnosis, $21(18.3 \%)$ went back to their previous jobs, most on a part-time basis (61.9\%), for an estimated average period of 12 months.

Factors involved in not returning to work were reported for 110 patients $(88 \%)$ and included the presence of significant treatment-related symptoms $(36.2 \%)$, disease-related symptoms or neurological deficits $(27.5 \%)$, neuropsychological impairment (15.7\%), a very poor functional status (7.8\%), clinical progression (7.8\%), personal preference $(2.9 \%)$, and welfare benefits (2\%) (Fig. 1).

\section{Univariate Analysis}

Table 3 shows the characteristics of patients returning to work and those not returning to work within the cohort 
TABLE 2. Employment status

\begin{tabular}{|c|c|c|c|c|c|}
\hline & 6-Mo FU & 12-Mo FU & 18-Mo FU & 24-Mo FU & Overall* \\
\hline No. of patients & 115 & 94 & 59 & 39 & \\
\hline Mean KPS score (range) & $76.3(30-100)$ & $73.5(30-100)$ & $72.2(30-100)$ & $72.3(40-100)$ & \\
\hline \multicolumn{6}{|l|}{ Seizure } \\
\hline No & $57(49.6 \%)$ & $44(46.8 \%)$ & $29(50.9 \%)$ & $19(48.7 \%)$ & \\
\hline Controlled by antiepileptic & $51(44.3 \%)$ & $43(45.7 \%)$ & $24(42.1 \%)$ & $19(48.7 \%)$ & \\
\hline Not controlled by antiepileptic & $7(6.1 \%)$ & $7(7.5 \%)$ & $4(7.0 \%)$ & $1(2.6 \%)$ & \\
\hline \multicolumn{6}{|l|}{ Return to job } \\
\hline No & $105(91.3 \%)$ & $81(86.2 \%)$ & $50(84.7 \%)$ & $28(71.8 \%)$ & $94(81.7 \%)$ \\
\hline Yes & $10(8.7 \%)$ & $13(13.8 \%)$ & $9(15.3 \%)$ & $11(28.2 \%)$ & $21(18.3 \%)$ \\
\hline Full time & $4(40 \%)$ & $6(46.2 \%)$ & $4(44.4 \%)$ & $3(27.3 \%)$ & $8(38.1 \%)$ \\
\hline Part time & $6(60 \%)$ & $7(53.8 \%)$ & $5(55.6 \%)$ & $8(72.7 \%)$ & $13(61.9 \%)$ \\
\hline
\end{tabular}

FU = follow-up.

Values are presented as the number of patients (\%) unless stated otherwise.

* Patient alive at the 6-month follow-up and returned to work at least part time for some length of time during follow-up.

of patients alive at 6 months after diagnosis. Patients resuming their previous employment had a significant difference in terms of mean age (45.9 vs 49.1 years; $p=0.03$ ) and rate of major comorbidities $(\mathrm{p}=0.02)$.

We observed a significant difference between the two groups regarding the distribution of socio-professional groups, with a higher rate of patients going back to work in the higher occupation categories $(\mathrm{p}=0.02)$ (Fig. 2). No significant difference was observed between employed and self-employed jobs $(\mathrm{p}=0.25)$. Returning to work was strongly associated with the performance status before and after surgery $(\mathrm{p}=0.002)$, with patients going back to work having a better performance score.

The distribution of the molecular characteristics between the two groups did not show a significant difference $(p=0.61$ and $p=0.81$ for IDH mutations and MGMT methylation, respectively).

We found a statistically significant difference in the type of surgery and resection quality between the two groups, with a higher rate of gross-total removal $(p=0.04)$ in the group that returned to work. The distribution of the performance values of the general population showed a pro- gressive decline, unlike the group of patients going back to work, which showed a slight improvement at the end of the radiochemotherapy and remained stable during the observation period (Fig. 3).

No statistically significant differences were found regarding radiological features (location, laterality, midline invasion, and presence of hydrocephalus) and the occurrence of complications after surgery.

Oncological treatment consisted of temozolomide radiochemotherapy in most patients (94\%) (Table 1), and there was no significant difference between the type of first-line oncological treatment in patients who returned to work and those who did not (Table 3).

\section{Discussion}

GBM diagnosis and treatment has a significant socioprofessional impact, with only a minority of patients being able to continue or resume their previous employment. ${ }^{5,7}$ In our cohort, of the 125 patients who were working before their diagnosis, only $18.8 \%$ went back to work, most on a part-time basis.

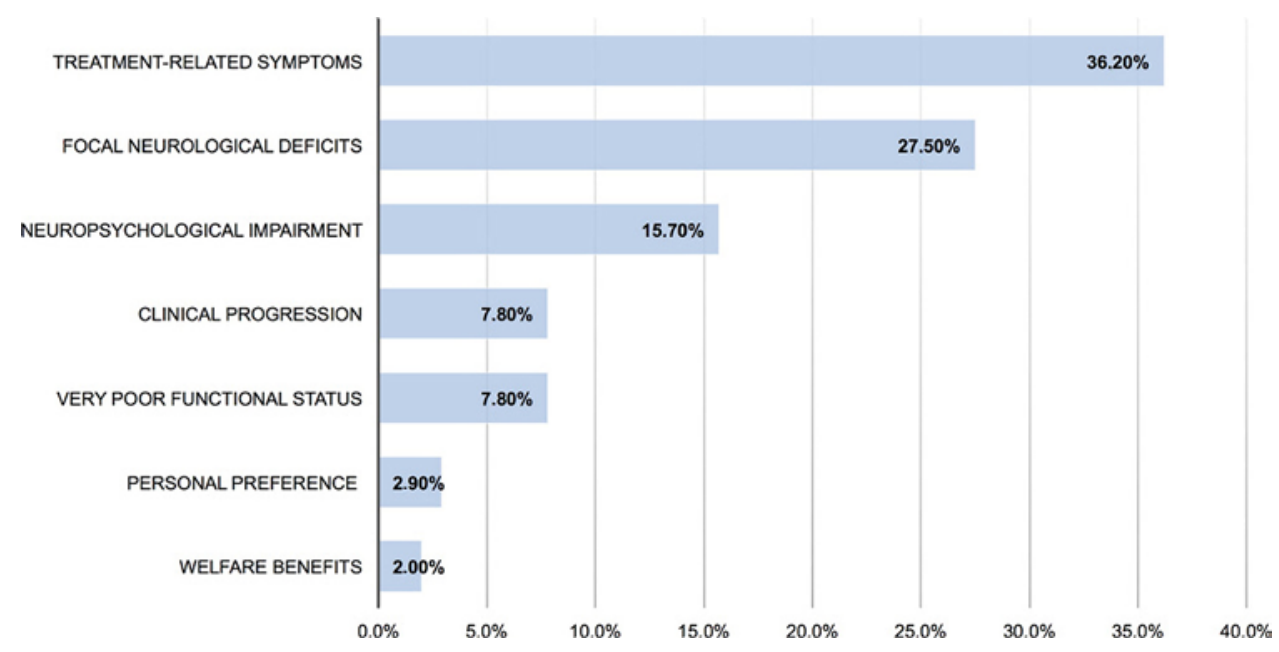

FIG. 1. Reasons for not returning to work. 
TABLE 3. Analysis of patient characteristics between those returning at least once to work and those not returning to work

\begin{tabular}{|c|c|c|c|}
\hline & Not Returning to Work $(n=94)$ & Returning to Work at Least Once $(n=21)$ & p Value \\
\hline Mean age in yrs & $49.1(8.3)$ & $45.9(8.2)$ & $0.03^{*}$ \\
\hline \multicolumn{4}{|l|}{ Sex } \\
\hline Female & $33(35.1)$ & $10(47.6)$ & $0.28 \dagger$ \\
\hline Male & $61(64.9)$ & $11(52.4)$ & \\
\hline Type of work & & & $0.25 \ddagger$ \\
\hline Employed worker & $85(90.4)$ & $17(80.9)$ & \\
\hline Self-employed worker & $9(9.6)$ & 4 (19.1) & \\
\hline Socio-professional category & & & $0.02 \ddagger$ \\
\hline Craftsmen, merchants, managing directors & $6(6.4)$ & $4(19.1)$ & \\
\hline Executive employees \& intellectual professions & $14(14.9)$ & $8(38.1)$ & \\
\hline Intermediary professions & $34(36.2)$ & $5(23.8)$ & \\
\hline Employees & $19(20.2)$ & $3(14.3)$ & \\
\hline Workers & $21(22.3)$ & $1(4.8)$ & \\
\hline Major comorbidities & & & $0.02 \ddagger$ \\
\hline No & $74(78.7)$ & $21(100.0)$ & \\
\hline Yes & $20(21.3)$ & $0(0.0)$ & \\
\hline \multicolumn{4}{|l|}{ Mean KPS score } \\
\hline Preop & $78.5(12.2)$ & $85.1(7.6)$ & $0.003^{*}$ \\
\hline At discharge & $79.6(11.9)$ & $87.1(7.8)$ & $0.002^{*}$ \\
\hline Laterality & & & $0.49 \ddagger$ \\
\hline $\mathrm{Rt}$ & $39(42.4)$ & $12(57.1)$ & \\
\hline $\mathrm{Lt}$ & $48(52.2)$ & $9(42.9)$ & \\
\hline Bilateral & $5(5.4)$ & $0(0.0)$ & \\
\hline Median & 2 & 0 & \\
\hline Location & & & $0.81 \ddagger$ \\
\hline Frontal & $29(30.8)$ & $8(38.1)$ & \\
\hline Parietal & $15(15.9)$ & $4(19.0)$ & \\
\hline Occipital & $29(30.8)$ & $6(28.6)$ & \\
\hline Temporal & $2(2.1)$ & $1(4.8)$ & \\
\hline Deep brain & 17 (18.1) & $2(9.5)$ & \\
\hline Brainstem & $2(2.1)$ & $0(0.0)$ & \\
\hline Midline invasion & & & $0.52 \ddagger$ \\
\hline No & $78(83.9)$ & $19(90.5)$ & \\
\hline Yes & $16(17.1)$ & $2(9.5)$ & \\
\hline Hydrocephalus & & & $0.99 \ddagger$ \\
\hline No & $89(94.7)$ & $20(95.2)$ & \\
\hline Yes & $5(5.3)$ & $1(4.8)$ & \\
\hline 1st surgery & & & $0.08 \ddagger$ \\
\hline Resection & $50(53.2)$ & $16(76.2)$ & \\
\hline Biopsy & $44(46.8)$ & $5(23.8)$ & \\
\hline Open biopsy & $10(22.7)$ & $1(20)$ & \\
\hline Neuronavigation-guided & $34(77.3)$ & $4(80)$ & \\
\hline Extent of surgery & & & $0.04 \dagger$ \\
\hline Biopsy & $44(46.8)$ & $5(23.8)$ & \\
\hline Total removal & $27(28.7)$ & $12(57.1)$ & \\
\hline Subtotal removal residual & $23(24.5)$ & 4 (19.1) & \\
\hline Recurrence needing surgery & & & $0.03 t$ \\
\hline No & $84(89.4)$ & $15(71.4)$ & \\
\hline Yes & $10(10.6)$ & $6(28.6)$ & \\
\hline Postsurgical complications & & & $0.99 \ddagger$ \\
\hline No & $78(83.0)$ & $18(85.7)$ & \\
\hline Yes & $16(17.0)$ & $3(14.3)$ & \\
\hline
\end{tabular}


» CONTINUED FROM PAGE 5

TABLE 3. Analysis of patient characteristics between those returning at least once to work and those not returning to work

\begin{tabular}{lccc}
\hline & Not Returning to Work $(\mathrm{n}=94)$ & Returning to Work at Least Once $(\mathrm{n}=21)$ & $\mathrm{p}$ Value \\
\hline First-line oncological treatment & & & $0.99 \ddagger$ \\
$\quad$ Chemotherapy + radiotherapy & $91(96.8)$ & $21(100)$ & \\
Other (chemotherapy or radiotherapy) & $3(3.2)$ & 0 & $0.61 \ddagger$ \\
\hline Molecular characterization & & & $0.81 \ddagger$ \\
IDH mutations & $5(5.4)$ & $9(9.5)$ & $0.0008 \dagger$ \\
MGMT methylation§ & $37(41.6)$ & & \\
\hline Death & & & $17(80.9)$ \\
No & $38(40.4)$ & $4(19.1)$ & \\
Yes & $56(59.6)$ &
\end{tabular}

Values are presented as the number of patients (\%) unless stated otherwise. Mean values are presented as the mean (SD). Boldface type indicates statistical significance.

* Wilcoxon test.

$\dagger$ Chi-square test.

$\ddagger$ Fisher exact test.

$\S$ Molecular data available for 110 patients in the group not returning to work and for 20 patients in the group returning to work.

Gzell et al. ${ }^{7}$ are the only authors so far to have directly addressed and analyzed return to work in a large representative cohort of GBM patients. They reported a prospective case series of 71 GBM patients who were working before diagnosis and treated with radiotherapy and chemotherapy with a mean follow-up of 15.5 months. They assessed data at 6 and 12 months after radiotherapy and found that $28 \%$ and $27 \%$ went back to work at the two time points. They found that baseline performance status and the presence of a neurological deficit was strongly associated with the ability to resume professional activity. Although these data differ from our results $(9 \%$ at 6 months and $14.1 \%$ at 12 months in our series vs $28 \%$ and $27 \%$ respectively in the series of Gzell) the two populations cannot be readily compared. The representation of the occupations varies between the two populations, with $20 \%$ of patients in manual labor in our cohort compared with only $7 \%$ in Gzell and colleagues' population.

Giovagnoli ${ }^{5}$ explored the quality of life in a case-control study of patients with stable disease after concomitant radiotherapy and chemotherapy for malignant brain tumors. They showed that $73 \%$ of patients resumed their previous occupations. However, in their series, only $14 \%$ of patients had GBM, and they were highly selected according to their selection criteria of stable disease, excluding patients with seriously focal and cognitive impairment.

Mandonnet et al. ${ }^{15}$ reported a consecutive series of 25 patients undergoing awake surgery for glioma. Of the 13 GBM patients included in their series, 11 benefited from a complete resection without new permanent motor or language deficits, and 7 were able to resume their job. However, this study also represents a selected subgroup

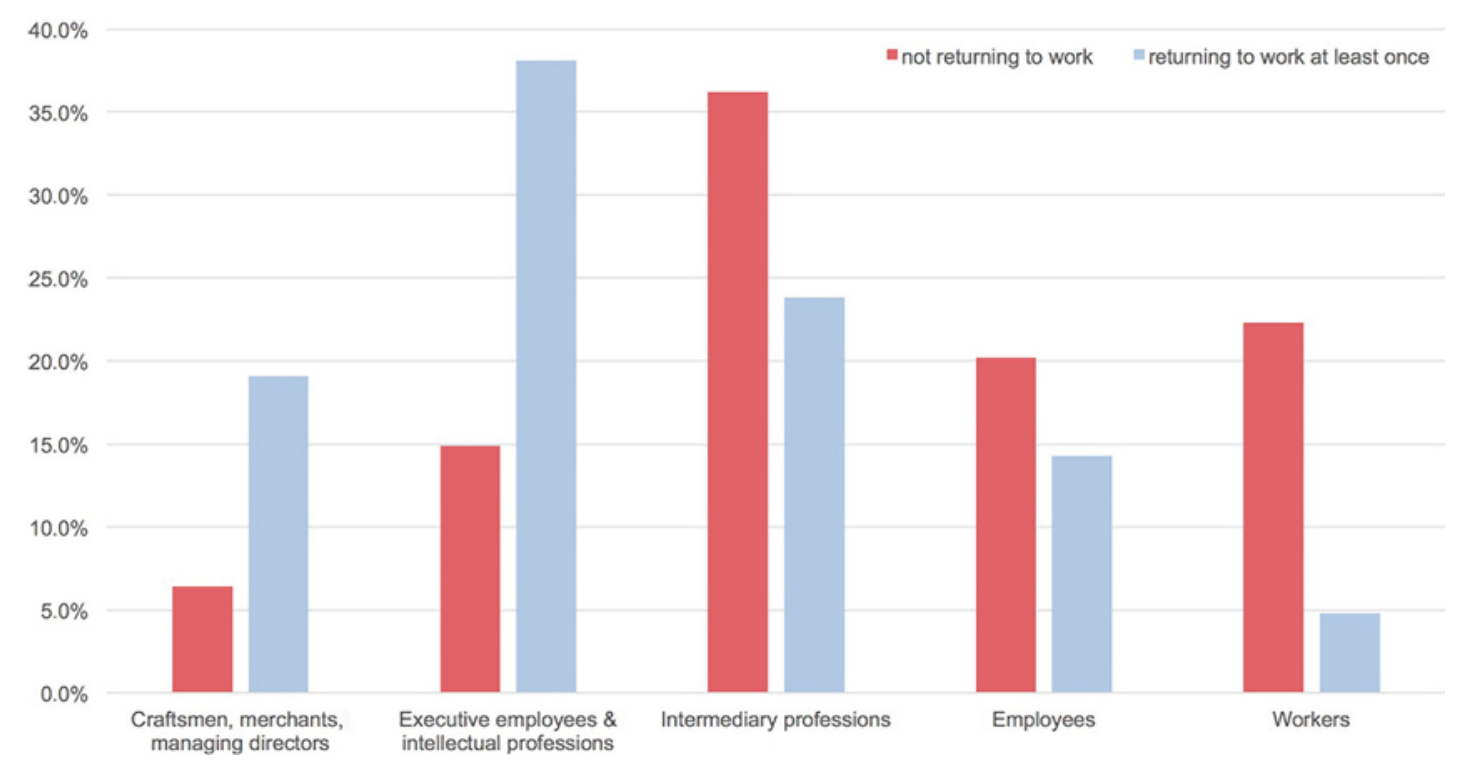

FIG. 2. Patients returning to work compared with patients not returning to work correlated with French socio-professional groups. 


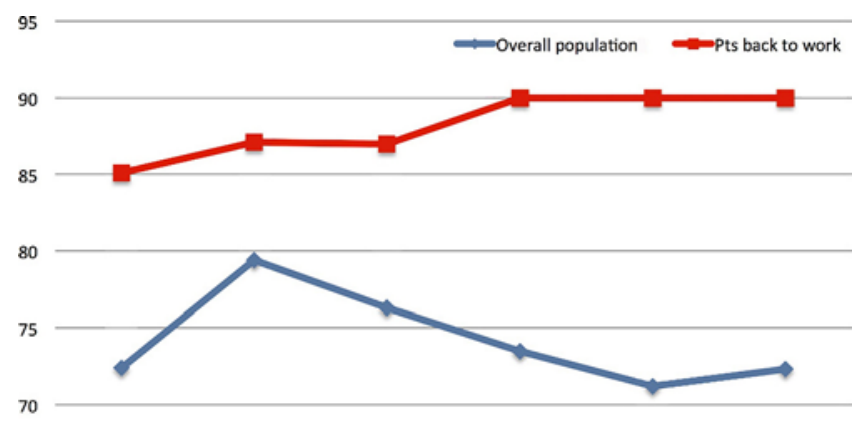

65

60

$\begin{array}{lllll}\text { Pre-op 1-week post-op } & \text { M6 } & \text { M12 } & \text { M18 } & \text { M24 }\end{array}$

FIG. 3. Performance status curves for the entire group versus those returning to work. KPS scores are shown on the $\mathrm{y}$-axis. $\mathrm{M}=$ month; $\mathrm{pts}$ = patients.

of patients and may hardly reflect the population of GBM patients.

Other studies ${ }^{12,20}$ have shown that between $44 \%$ and $60 \%$ of glioma patients were able to continue their previous employment; however, the sample size was very small (13 patients in the study of Schmidinger et al. ${ }^{20}$ ), and GBM patients represented a minority of the population $(20 \%$ in the study of Kleinberg et al. ${ }^{12}$ ).

Although many studies tend to associate different glial tumors in functional analysis, it is undeniable that the different aggressiveness and development of gliomas have a different impact on functional and return to work outcomes in each group. Concerning anaplastic gliomas, Habets et al. ${ }^{8}$ evaluated HRQOL and cognitive functioning in 32 of 37 long-term survivors with anaplastic glioma included in European Organization for Research and Treatment of Cancer study. They showed that $41 \%$ of progression-free patients were able to resume their work and $81 \%$ could live independently.

The longer median overall survival of the patients in our study (22.9 months) stems from the fact that this study sample is a selective population.

There is no doubt that the increased incidence of GBM and the improvement in the treatment outcome will result in a higher prevalence of survivors, ${ }^{12}$ but the HRQOL and functional outcome of these patients has so far been the

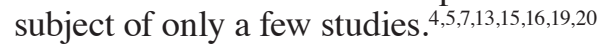

Paquette et al. ${ }^{19}$ identified future uncertainty in unresectable GBMs as an independent predictor factor for OS, which was in line with financial worries. The ability to provide for one's economic self-sustenance not only impacts a person's socioeconomic quality of life but also affects the sense of future certainty and influences his or her self-worth and can be considered as a parameter of social reintegration..$^{3,14}$

Cancer survivors have been shown to be 1.37 times more likely to be unemployed, and a large meta-analysis showed that the highest risk for unemployment was among survivors of nervous system cancer (relative risk 1.78). ${ }^{1}$ GBM patients face a significant burden of tumor- and treatment-related symptoms and long-term survivors of high-grade gliomas often encounter a progressive neurological deterioration, psychological distress, personality changes, and neuropsychological impairment., ${ }^{9,18}$

The impact of cognitive dysfunction on the capability of resuming professional ability is of utmost importance, and it appears to be the main reason in almost $16 \%$ of patients in our series. Neuropsychological testing has also demonstrated that more than $50 \%$ of long-term GBM survivors face a significant cognitive decline even in the absence of symptoms..$^{1,21,22}$ This suggests that the implications of treatment in cognitive decline also play a significant role and may adversely lead to increased fatigue in the short term and cognitive dysfunction in the long term. ${ }^{6}$

Fatigue appears to be the most significant symptom facing patients during the concomitant radiotherapy and chemotherapy. In our series, fatigue and treatment-related symptoms were the main reasons for not going back to work for $36 \%$ of patients.

As shown in the comparative analysis, both groups demonstrated a slight decline in their performance in correlation with the chemotherapy treatment period, and subsequently the two curves diverge.

There is no doubt that the ability to continue the previous employment depends on multiple variables, including physical demands of the job and patient's expectations and job involvement. In our series, we have found a significant difference in the distinct socio-professional groups with patients returning to work in the higher-occupation categories, and manual or physically demanding work was negatively associated with the ability to return to work $(38.1 \%$ vs $4.8 \%$ ).

Although we showed that gross-total removal was significantly associated with the ability to return to work compared with biopsy, this finding should be evaluated in a larger multivariate cohort analysis to assess its causal relationship. As a matter of fact, this factor is subject to the limitation imposed by a selection bias of patients who undergo biopsy based on factors such as larger tumor size, multifocality, surgically inaccessible locations, and poorer functional status, and the fact that the amount of resection is associated with survival, and prolonged survival is possibly related to returning to work.

Our data confirm that younger age, lack of associated comorbidities, and better performance status are associated with a greater proportion of patients resuming their professional activity.

Although tumor location was not found to be related to work activity, this finding must be interpreted with caution due to the multiplicity of location and the difficulty of statistically representing the numerous combinations with each precise functional region and laterality. It is intuitive that defining tumor location based on brain lobes expresses a topographical simplification that does not take into account the different functional areas of each cerebral lobe. It appears obvious that localization in an eloquent zone might be related to a lower functional state and orient the diagnostic gesture to a biopsy.

Beyond some intuitive conclusions, the exact socioeconomic impact of malignant brain tumor is far from being precisely assessed. Even though we have previously emphasized the importance of the social and economic health 
context, we have not been able to refine the results according to the income and social security cover due to the lack of such data.

Being a retrospective review, data related to reasons for not returning to work were available only in $88 \%$ of patients and are purely descriptive. The critical analysis of reason for not returning to work should be assessed in a prospective way, and its interpretation should be related to the social and economic health context.

Although this study has limitations related to its retrospective observational nature, which is associated with several methodological drawbacks common to retrospective data, we provided data on the return to work in the largest cohort of working-age GBM patients published to date.

\section{Conclusions}

The representation of the various professional categories in our series better outlines the socio-professional impact of this pathology and provides a representative picture of reality when it comes to a specific functional outcome such as employment following chemoradiotherapy for GBM.

\section{References}

1. de Boer AG, Taskila T, Ojajärvi A, van Dijk FJ, Verbeek JH: Cancer survivors and unemployment: a meta-analysis and meta-regression. JAMA 301:753-762, 2009

2. Efficace F, Bottomley A: Assessing HRQOL: a neglected issue for high-grade glioma. Lancet Oncol 4:11-12, 2003

3. Feuerstein M, Todd BL, Moskowitz MC, Bruns GL, Stoler MR, Nassif T, et al: Work in cancer survivors: a model for practice and research. J Cancer Surviv 4:415-437, 2010

4. Gately L, McLachlan SA, Dowling A, Philip J: Life beyond a diagnosis of glioblastoma: a systematic review of the literature. J Cancer Surviv 11:447-452, 2017

5. Giovagnoli AR: Quality of life in patients with stable disease after surgery, radiotherapy, and chemotherapy for malignant brain tumour. J Neurol Neurosurg Psychiatry 67:358-363, 1999

6. Gregor A, Cull A, Traynor E, Stewart M, Lander F, Love S: Neuropsychometric evaluation of long-term survivors of adult brain tumours: relationship with tumour and treatment parameters. Radiother Oncol 41:55-59, 1996

7. Gzell C, Wheeler H, Guo L, Kastelan M, Back M: Employment following chemoradiotherapy in glioblastoma: a prospective case series. J Cancer Surviv 8:108-113, 2014

8. Habets EJ, Taphoorn MJ, Nederend S, Klein M, Delgadillo D, Hoang-Xuan K, et al: Health-related quality of life and cognitive functioning in long-term anaplastic oligodendroglioma and oligoastrocytoma survivors. J Neurooncol 116:161-168, 2014

9. Heimans JJ, Taphoorn MJ: Impact of brain tumour treatment on quality of life. J Neurol 249:955-960, 2002

10. Johnson DR, O'Neill BP: Glioblastoma survival in the United States before and during the temozolomide era. J Neurooncol 107:359-364, 2012

11. Klein M, Taphoorn MJ, Heimans JJ, van der Ploeg HM, Vandertop WP, Smit EF, et al: Neurobehavioral status and health-related quality of life in newly diagnosed high-grade glioma patients. J Clin Oncol 19:4037-4047, 2001

12. Kleinberg L, Wallner K, Malkin MG: Good performance status of long-term disease-free survivors of intracranial gliomas. Int J Radiat Oncol Biol Phys 26:129-133, 1993

13. Liu R, Page M, Solheim K, Fox S, Chang SM: Quality of life in adults with brain tumors: current knowledge and future directions. Neuro Oncol 11:330-339, 2009
14. Main DS, Nowels CT, Cavender TA, Etschmaier M, Steiner JF: A qualitative study of work and work return in cancer survivors. Psychooncology 14:992-1004, 2005

15. Mandonnet E, De Witt Hamer P, Poisson I, Whittle I, Bernat AL, Bresson D, et al: Initial experience using awake surgery for glioma: oncological, functional, and employment outcomes in a consecutive series of 25 cases. Neurosurgery 76:382-389, 2015

16. Mauer M, Stupp R, Taphoorn MJ, Coens C, Osoba D, Marosi $\mathrm{C}$, et al: The prognostic value of health-related quality-of-life data in predicting survival in glioblastoma cancer patients: results from an international randomised phase III EORTC Brain Tumour and Radiation Oncology Groups, and NCIC Clinical Trials Group study. Br J Cancer 97:302-307, 2007

17. Meyers CA, Hess KR: Multifaceted end points in brain tumor clinical trials: cognitive deterioration precedes MRI progression. Neuro Oncol 5:89-95, 2003

18. Osoba D, Brada M, Yung WK, Prados M: Health-related quality of life in patients treated with temozolomide versus procarbazine for recurrent glioblastoma multiforme. J Clin Oncol 18:1481-1491, 2000

19. Paquette B, Vernerey D, Chauffert B, Dabakuyo S, Feuvret L, Taillandier L, et al: Prognostic value of health-related quality of life for death risk stratification in patients with unresectable glioblastoma. Cancer Med 5:1753-1764, 2016

20. Schmidinger M, Linzmayer L, Becherer A, Fazeny-Doemer B, Fakhrai N, Prayer D, et al: Psychometric- and quality-oflife assessment in long-term glioblastoma survivors. J Neurooncol 63:55-61, 2003

21. Scott JN, Rewcastle NB, Brasher PM, Fulton D, MacKinnon JA, Hamilton M, et al: Which glioblastoma multiforme patient will become a long-term survivor? A population-based study. Ann Neurol 46:183-188, 1999

22. Smoll NR, Schaller K, Gautschi OP: Long-term survival of patients with glioblastoma multiforme (GBM). J Clin Neurosci 20:670-675, 2013

23. Steinbach JP, Blaicher HP, Herrlinger U, Wick W, Nägele T, Meyermann R, et al: Surviving glioblastoma for more than 5 years: the patient's perspective. Neurology 66:239-242, 2006

24. Stupp R, Hegi ME, Mason WP, van den Bent MJ, Taphoorn MJ, Janzer RC, et al: Effects of radiotherapy with concomitant and adjuvant temozolomide versus radiotherapy alone on survival in glioblastoma in a randomised phase III study: 5-year analysis of the EORTC-NCIC trial. Lancet Oncol 10:459-466, 2009

25. Zouaoui S, Rigau V, Mathieu-Daudé H, Darlix A, Bessaoud F, Fabbro-Peray P, et al: [French brain tumor database: general results on 40,000 cases, main current applications and future prospects.] Neurochirurgie 58:4-13, 2012 (Fr)

\section{Disclosures}

The authors report no conflict of interest concerning the materials or methods used in this study or the findings specified in this paper.

\section{Author Contributions}

Conception and design: Starnoni, Guyotat. Acquisition of data: Starnoni, Idriceanu, Meyronet. Analysis and interpretation of data: Starnoni, Berthiller, Guyotat. Drafting the article: Starnoni. Critically revising the article: d'Hombres, Ducray, Guyotat. Statistical analysis: Berthiller. Administrative/technical/material support: Meyronet. Study supervision: Ducray, Guyotat.

\section{Correspondence}

Daniele Starnoni: Pierre Wertheimer University Hospital, CHU de Lyon, Bron, France. danielestarnoni@gmail.com. 